\title{
Management of chronic diarrhea in HIV-infected patients: current treatment options, challenges and future directions
}

This article was published in the following Dove Press journal:

HIVIAIDS - Research and Palliative Care

9 November 2010

Number of times this article has been viewed

\author{
Lidia Elfstrand \\ Claes-Henrik Florén \\ Department of Medicine, Division \\ of Clinical Sciences, Skåne University \\ Hospital, Lund University, Lund, \\ Sweden
}

\begin{abstract}
Diarrhea is a common clinical manifestation of HIV infection regardless of whether the patients have AIDS. HIV and malnutrition tend to occur in the same populations, the underprivileged and resource-poor. Malnutrition increases severity and mortality of infection. Occurrence of chronic diarrhea in HIV-infected patients, gut status and pathogenic agents, nutritional status and the crucial role of nutrition are reviewed. Bovine colostrum-based food can be useful for managing chronic diarrhea in HIV-infected patients, enhancing both nutritional and immunological status.
\end{abstract}

Keywords: HIV, diarrhea, nutrition, bovine colostrum, CD4+

\section{Introduction}

Infection with HIV imposes monumental suffering on afflicted individuals, and in the developing world in particular it places a great burden on the medical system. It is generally estimated that close to $100 \%$ of HIV-positive patients in the developing world may suffer from chronic diarrhea, as estimated on a cumulative life-time incidence, but the situation in the developed world is better, where a lower percentage of HIV-positive patients suffer from diarrhea. ${ }^{1}$ It is well known that HIV destroys the immune system and renders patients susceptible to opportunistic infections. The virus also leads to enteropathy, causing a partial villous atrophy with subsequent malabsorption. ${ }^{2}$

Patients are usually diagnosed with diarrhea when three or more defecations occur per day; chronic diarrhea is diagnosed when this pattern is sustained for more than 3 months. Chronic diarrhea is not a life-threatening condition, but it can severely diminish quality of life. In conditions of poor sanitation it places a particularly heavy psychological and social burden on afflicted patients. Chronic diarrhea in HIV patients is also an AIDS-defining condition, according to World Health Organization (WHO) criteria.

\section{Etiological pathogenic agents}

In a situation where immunodeficiency develops in HIV-infected individuals, one of the hardest-hit organs is the intestine. First, the enterocytes can undergo atrophy, as a result of the HIV virus infecting the enterocytes and damaging their function. ${ }^{2,3}$ Second, as the intestine is the largest immunological organ in the body, destruction of immunocompetent cells in the intestine will cause intestinal dysfunction, which is among several symptoms observed in diarrhea.

Numerous studies have shown that diarrhea in HIV/AIDS can be caused by common pathogens, including viruses, fungi, bacteria and helminthes. What also complicates
Correspondence: Lidia Elfstrand

Norra Skolgatan 5,

2 II 52 Malmö, Sweden

Tel +46704 92067I

Email lidia@foodorientation.com 
the situation is that, as well as infection by regular pathogens, the risk of infection by opportunistic agents increases as the patients become immunocompromised. ${ }^{4-7}$ There is however no specific mix of pathogens and opportunistic agents present in HIV-associated diarrhea, but the enteric pathogens vary from patient to patient and from country to country.

One pathogen, which in immunocompromised HIV-positive individuals can cause chronic diarrhea, is Cryptosporidium. In immunocompetent individuals this infection is usually self-limiting, but not in HIV-positive immunocompromised individuals. Generally, no effective treatment of chronic diarrhea in HIV-positive immunocompromised individuals is available, but the mainstay of treatment is treatment with antiretroviral therapy (ART).

Numerous studies have documented the pathogens that can be found in patients with HIV-associated diarrhea. ${ }^{4-7}$ The consensus seems to be that all known pathogens and intestinal opportunistic agents can cause chronic diarrhea. A diagnostic work-up is needed for each patient, if possible. The work-up can be limited to fecal cultures and microscopy, but may also include rectal and/or other intestinal biopsies. ${ }^{4-7}$

Some studies report high yields of identified causative agents while others report low figures. Diarrhea is not life-threatening, but can severely hamper daily activities and lower quality of life. Diagnostic efforts should be made to try to find the causative agent and to treat with antibiotics and other specific therapies if possible. One study suggested that in immunocompetent individuals, defined as those with a CD4+ count of $>200 / \mu \mathrm{L}$, the infecting agents were ordinary pathogens, while in individuals with a CD4+ count of $<200 / \mu \mathrm{L}$, the infecting agents were opportunistic agents. ${ }^{8}$

However, the mainstay of therapy in chronic diarrhea of HIV-positive individuals in countries where it is economically and socially feasible, is treatment with highly active ART (HAART).

The risk of chronic diarrhea in HIV-positive patients has been reduced dramatically where HAART is accessible, and the decision to introduce HAART is now taken at higher CD4+ levels. However, HAART is associated with lipodystrophy, which in turn is related to insulin resistance and its metabolic complications, such as impaired glucose tolerance, diabetes and hypertriglyceridimia. ${ }^{9-11}$

\section{The pivotal role of CD4+ levels}

As the HIV infection progresses and the viral load increases, the CD4+ count will decrease. CD4+ lymphocytes are
T-helper cells, and are directly struck in the HIV virus attack as the HIV virus enters these through the CD4+ receptor. After entering these key cells in the immunological defense system, the HIV virus rapidly proliferates and destroys these cells. Where the CD4+ count is $<200 / \mu \mathrm{L}$, AIDS exists by definition.

A variety of ARTs are now available, which can decrease the viral load and increase the CD4+ count. In affluent societies HIV infection is not considered a deadly disease, but a chronic illness, which demands constant and varied antiretroviral medication to slow down virus replication, with the goal of achieving a low number of viral copies in the blood and a reciprocally high number of CD4+ cells. ${ }^{12,13}$ This is however not possible in developing countries, where nutrition and sanitation are poor, which increases the risk of protracted chronic diarrhea.

Although at one predetermined CD4+ level there is an indication for treatment with HAART, different studies suggest that with proper nutritional support the chances of HAART treatment reducing disease burden increase. ${ }^{14}$ Also, as HAART treatment can induce adverse effects, especially metabolic side effect, and also diarrhea, the longer the introduction of HAART is postponed the better. So postponing the introduction of HAART by introducing a nutritional treatment of a varied and healthy diet, which is rich in micronutrients, or by adding nutritional additives, for example, preparations rich in colostrum, could be very rewarding.

\section{The role of nutrition in hindering progression of HIV disease}

There is good consensus that malnutrition has a negative impact on survival in HIV disease, even when ART is at hand. In addition, malnutrition at introduction of ART is associated with early mortality, ${ }^{14-18}$ with a low body mass index as its independent predictor. ${ }^{19}$

Nutritional support can result in restored intestinal function ${ }^{20}$ and weight gain in HIV-infected children. ${ }^{21}$ The patients reported in both these studies were enrolled before HAART was available. An increase in CD4+ cell numbers could be observed in one of these studies, ${ }^{20}$ especially if nutritional support were provided before a terminal stage of HIV infection, whereas nutritional support of children with advanced HIV infection reported by Rollins et $\mathrm{al}^{21}$ resulted in sustained weight gain but not improved CD4+ count or survival.

One question that has attracted a great deal of attention is whether micronutrient supplementation can decrease 
wasting in HIV disease. Wasting is probably caused by several mechanisms, where diarrheal disease caused by enteric pathogens, opportunistic infection and enterocyte destruction are among the causative factors. One study from Tanzania showed that a combination of vitamins $\mathrm{C}$ and $\mathrm{E}$ and vitamin $\mathrm{B}$ complex slowed weight decrease in HIV-infected women and delayed HIV progression significantly. ${ }^{22}$ Another study, which was a randomized trial comparing vitamin supplementation with placebo on HIV disease progression, showed that multivitamins increased CD4+ and CD8+ counts and lowered viral load compared with placebo. ${ }^{23}$ Thus, in this study multivitamins slowed progression of HIV disease. However, a Cochrane study conducted by Irlam et al found no conclusive evidence that micronutrients reduce morbidity or mortality in HIV-infected adults but the authors concluded that the WHO recommendations for micronutrient supplementations should be followed. ${ }^{24}$

However, micronutrient supplementation is just one part of good general nutrition and the overall recommendation should be that HIV-infected patients, if it is socially and economically feasible, should have a good and varied nutritional intake.

Many publications can be found on the effect of micronutrient supplements on HIV progression in both children and adults, ${ }^{22,23,25,26}$ but there are few reports on the role of macronutrients for improving survival of HIV-infected individuals. However, it has been shown that HIV-positive patients with opportunistic illness have increased rates of catabolism and require greater protein intake to minimize loss of lean body mass. ${ }^{27}$ An anticatabolic effect of nutritional supplements (containing $2510 \mathrm{~kJ}$, complete macroand micronutrients) combined with dietary counseling in HIV-infected subjects was reported by Berneis et al. ${ }^{28}$ The diminished whole body protein catabolism resulted in a change of body composition (increased lean mass, decreased fat mass). Current evidence supporting macronutrients supplementation for malnourished HIV-infected adults has been recently reviewed by Koethe et al. ${ }^{29}$ The authors suggested a range of variables for future macronutrient-based trials for malnourished HIV-infected persons in order to succeed with ART programs.

\section{The role of a structurally intact small intestine}

As early as 1984, Kotler and associates described an HIV-associated enteropathy with structural resemblance to celiac disease. ${ }^{3}$ There is thus a reduced villous height in HIV infection and also a CD4+ mucosal lymphopenia and an increase in CD8+ lymphocytes. Further, there is an enhanced intestinal permeability, possibly leading to a greater influx of lipopolysaccharides, which are bacterial antigens from Gram-negative bacteria. ${ }^{30}$ This can clearly be a factor that causes diarrheal disease and exacerbates or causes malnutrition.

\section{Role of bovine colostrum in treatment of HIV- associated diarrhea}

A few observational studies have been published on the effect of bovine colostrum preparations in HIV-associated diarrhea. ${ }^{31-36}$ In one of these a substantial therapeutic effect was reported in 25 patients, $40 \%$ of whom had a complete remission and $24 \%$ a partial remission of diarrheal disease post treatment. ${ }^{32}$ In other studies, the efficacy of treatment with colostrum preparations was reported in Cryptosporidium-associated diarrhea in patients with AIDS. ${ }^{34-36}$

Bovine colostrum is the first milk the lactating cow gives to the suckling calf during the first days of life. Its composition is quite different from that of ruminant milk in established lactation and is characterized by its very high level of several bioactive components: immunoglobulins, growth factors, some whey proteins and proteinase inhibitors, vitamins and minerals. The biological function of colostrum is to, through its composition, provide the calf with passive immunity, support calf growth and prevent gastrointestinal infections until the calf's own immune system is fully functional.

The immune system of the newborn has been shown to be stimulated by colostrum which works to speed up the maturation of B-lymphocytes. Colostral immunoglobulins, the amount of which can be 50-250 times higher than in milk during established lactation, ${ }^{37}$ may both treat and prevent viral and bacterial infections. In addition, colostrum contains lactoferrin, a protein that has been shown to transport essential iron to hematopoietic cells and prevent harmful viruses and bacteria from getting the iron they need for their growth. Bovine colostrum is also known to contain growth factors, the major forms of which are IGF- 1 and TGF- $\beta 2$, the composition of which is identical to that found in humans. They can promote mucosal recovery and gut integrity in patients with severe diarrheal illness. A study in rats showed that bovine colostrum preparation can heal the injurious effects of nonsteroidal anti-inflammatory drugs, which cause increased gastrointestinal permeability. ${ }^{38}$ High amounts of $\mathrm{Zn}$ and Se, whose importance to the immune system is well 
known, have also been reported in colostrum. ${ }^{39}$ Low levels of plasma $\mathrm{Zn}$ and Se are associated with the deterioration of immune system and higher mortality. ${ }^{40,41}$

We have used ColoPlus ${ }^{\circledR}$ IMCARE (ColoPlus, Malmö, Sweden), a therapeutic food product based on bovine colostrum powder, in studies on HIV/AIDS patients suffering from diarrhea and malnutrition. The product was developed for this application. The nutritional value of ColoPlus ${ }^{\circledR}$ IMCARE is shown in Table 1. ColoPlus ${ }^{\circledR}$ IMCARE has been tested in clinical studies on HIV-positive patients in two settings in Nigeria ${ }^{42}$ and Uganda. ${ }^{43}$ Both studies showed that ColoPlus ${ }^{\circledR} I M C A R E$ can alleviate diarrheas, increase body weight and induce significant increase in CD4+ levels.

ColoPlus $^{\circledR}$ IMCARE is made and delivered in powder form and has to be mixed with water to obtain a porridge suitable for consumption. No side effects have been reported. The proposed portion size, suitable for flexibility of use and handling, is 25- or 50-g sachets.

ColoPlus $^{\circledR}$ IMCARE consists of two parts, a bioactive part (colostrum) and a vehicle. The vehicle is composed of organic particulate matter, which is used to slow down and control the time required to empty the stomach, thus prolonging transit time of bioactives through the digestive tract, increasing contact time with the mucosal surface of the gastrointestinal tract and causing local immunological response. Survival and resistance of the bioactive parts in the gastrointestinal tract are also increased.

Colostrum powder quality is of crucial importance for the therapeutic effect of the product. Industrial processing of colostrum for ColoPlus ${ }^{\circledR}$ IMCARE manufacture is carried out carefully to prevent its balanced system from distortion of bioactive peptides and protein denaturation. In product formulation, a principle of "entire colostrum system" is used. All the bioactive components in colostrum act synergistically in such a way that improves the overall

Table I Nutritional value of ColoPlus ${ }^{\circledR}$ IMCARE

\begin{tabular}{ll}
\hline Energy value & $1650 \mathrm{~kJ} / 360 \mathrm{kcal}$ \\
Protein, g & $23.0 \pm 2.0$ \\
$\mathrm{lgG}, \mathrm{g}$ & $7.4 \pm 1.2$ \\
Fat, g & $2.0 \pm 0.2$ \\
Carbohydrate, g & $69.0 \pm 2.0$ \\
Lactose, g & 6.0 \\
Sucrose, g & 4.0 \\
Ash, g & $2.0 \pm 0.2$ \\
Dry matter, g & $96.0 \pm 0.5$
\end{tabular}

Note: values are per $100 \mathrm{~g}$ dry product. effect of each individual component. Without further fractionation, some of the components that make up colostrum, such as carbohydrates, proteins and salts, can protect more sensitive components of colostrum from inactivation during the conventional processing used in the dairy industry. ${ }^{44}$ The quality is determined by the IgG content, which is an established marker for liquid colostrum quality, with growth factors being positively correlated with Ig levels. ${ }^{44}$

To ensure that the effects of ColoPlus ${ }^{\circledR}$ IMCARE were sustained, CD4+ count, body weight, and frequency of bowel movements were measured in the two above mentioned studies, 2 and 5 weeks after termination of ColoPlus therapy. In both studies a sustained effect of ColoPlus, as measured by the above mentioned parameters, was apparent. The therapeutic effect of ColoPlus ${ }^{\circledR}$ IMCARE was shown to last for at least 5 weeks.

Thus, in these studies ColoPlus ${ }^{\circledR} I M C A R E$ not only significantly increased CD4+ level but also alleviated diarrhea and sustained weight gain. Thus, this colostrum-based food product, through its bioactive content combined with micronutrients and high quality macronutrients, such as essential amino acids and carbohydrates, could improve both the immune and nutritional status in HIV-infected individuals. $^{42,43}$

\section{Challenges and future directions}

Challenges for the future are partly socioeconomic and partly medical. Socioeconomically, the overall aim for HIV-associated diarrhea should be that all disease-stricken individuals should have access to HAART. Of course, a proper medical investigation and directed therapy should be undertaken for each individual. Once this is in place, the challenge is to ensure that antiretroviral agents can act optimally. In doing so, there should be a high emphasis on good and adequate nutritional therapy. Also, we believe that special nutritional regimes such as colostrum-based therapies could have a role in this situation, especially as an adjunct to treatment of HIV-associated diarrhea.

However, the world's resources are limited, especially in the developing countries. One priority would under such circumstances is to try to postpone the need for antiretroviral agents or HAART by introducing adequate nutritional support. Colostrum-based remedies can have a crucial role in sustaining CD4+ levels and can also diminish viral load, thereby saving time until the introduction of antiretroviral agents. Adverse effects, especially metabolic, of ART, 
including HAART, means that their introduction should be delayed as long as possible.

An ongoing trial, the CORAL study, is measuring the effect on CD4+ counts of combining hyperimmune bovine colostrum with the antiretroviral drug raltegravir. ${ }^{45}$

\section{Disclosure}

The authors report no conflicts of interest.

\section{References}

1. Wilcox CM, Rabeneck L, Friedman S. AGA technical review: malnutrition and cachexia, chronic diarrhea, and hepatobiliary disease in patients with human immunodeficiency virus infection. Gastroenterology. 1996;111:1724-1752.

2. Craig RM, Carlson S, Ehrenpreis E. Acquired immunodeficiency syndrome enteropathy: a perspective. Compr Ther. 1995;21: 184-188.

3. Kotler DP, Gaetz HP, Lange M, Klein EB, Holt PR. Enteropathy associated with the acquired immunodeficiency syndrome. Ann Intern Med. 1984;101:421-428.

4. Blanshard C, Francis N, Gazzard BG. Investigation of chronic diarrhea in acquired immunodeficiency syndrome. A prospective study of 155 patients. Gut. 1996;39:824-832.

5. Gumbo T, Sarbah S, Gangaidzo IT, et al. Intestinal parasites in patients with diarrhea and human immunodeficiency virus infection in Zimbabwe. AIDS. 1999;13:819-821.

6. Kulkarni SV, Kairon SS, Sane PS, et al. Opportunistic parasitic infections in HIV/AIDS patients presenting with diarrhoea by the level of immunesuppression. Indian J Med Res. 2009;130:63-66.

7. Chen X-M, Keithly JS, Paya CV, LaRusso NF. Cryptosporidiosis. N Engl J Med. 2002;346:1723-1731.

8. Call SA, Heudebert G, Saag M, Wilcox CM. The changing etiology of chronic diarrhea in HIV-infected patients with CD4 cell counts less than 200 cells $/ \mathrm{mm}^{3}$. Am J Gastroenterol. 2000;95:3142-3146.

9. Kotler DP. Nutritional alterations associated with HIV infection. J Acquir Immune Defic Syndr. 2000;25:S81-S87.

10. Shevitz A, WankeCA, Falutz J, Kotler DP. Clinical perspectives on HIV-associated lipodystrophy syndrome: an update. AIDS. 2001;15: 1917-1930.

11. Chen D, Misra A, Garg A. Clinical review 153: Lipodystrophy in human immunodeficiency virus-infected patients. J Clin Endocrinol Metab. 2002;87:4845-4856.

12. Vella S, Palmisano L. Antiretroviral therapy: state of the HAART. Antiviral Res. 2000;45:1-7.

13. Brady M, Oleske J, Williams P, et al. Declines in mortality rates and changes in causes of death in HIV-1-infected children during the HAART era. J Acquir Immune Defic Syndr. 2010;53:86-94.

14. Paton NI, Sangeetha S, Earnest A, Bellamy R. The impact of malnutrition on survival and the CD4 count response in HIV-infected patients starting antiretroviral therapy. HIV Med. 2006;7:323-330.

15. Stringer JSA, Zulu I, Levy J, et al. Rapid scale-up of antiretroviral therapy at primary care sites in Zambia. JAMA. 2006;296:782-793.

16. Zachariah R, Fitzgerald M, Massaquoi M, et al. Risk factors for high early mortality in patients on antiretroviral treatment in a rural district of Malawi. AIDS. 2006;20:2355-2360.

17. Johannessen A, Naman E, Kivuyo SL, et al. Virological efficacy and emergence of drug resistance in adults on antiretroviral treatment in rural Tanzania. BMC Infect Dis. 2009;9:108.

18. Sherlekar S, Udipi SA. Role of nutrition in the management of HIV infection/AIDS. J Indian Med Assoc. 2002;100:385-390.

19. Koethe JR, Heimburger DC. Nutritional aspects of HIV-associated wasting in sub-Saharan Africa. Am J Clin Nutr. 2010;91:1138-1142.
20. Guarino A, Spagnuolo MI, Giacomet V, et al. Effects of nutritional rehabilitation on intestinal function and on CD4 cell number in children with HIV. J Pediatr Gastroenterol Nutr. 2002;34:366-371.

21. Rollins NC, van den Broeck J, Kindra G, Pent M, Kasambira T, Bennish ML. The effect of nutritional support on weight gain of HIV-infected children with prolonged diarrhoea. Acta Pediatrica. 2007;96:62-68.

22. Fawzi WW, Msamanga GI, Spiegelman D, et al. A randomized trial of multivitamin supplements and HIV disease progression and mortality. N Engl J Med. 2004;351:1367-1377.

23. Villamor E, Saathoff E, Manji K, Msamanga G, Hunter DJ, Fawzi WW. Vitamin supplements, socioeconomic status, and morbidity events as predictors of wasting in HIV-infected women from Tanzania. Am J Clin Nutr. 2005;82:857-865.

24. Irlam JJH, Visser MME, Rollins NN, Siegfried N. Micronutrient supplementation in children and adults with HIV infection. Cochrane Database Syst Rev. 2005;4:CD003650.

25. Campa A, Shor-Posner G, Indacochea F, et al. Mortality risk in selenium-deficient HIV-positive children. J Acquir Immune Defic Syndr Hum Retrovirol. 1999;20:508-513.

26. Fawzi WW, Mbise RL, Hertzmark E, et al. A randomized trial of vitamin A supplements in relation to mortality among human immunodeficiency virus-infected and uninfected children in Tanzania. Pediatr Infect Dis J. 1999;18:127-133.

27. Grunfeld C, and Feingold KR. Metabolic disturbances and wasting in the acquired immunodeficiency syndrome. $N$ Engl J Med. 1992; 327:329-337.

28. Berneis K, Battegay M, Bassetti S, et al. Nutritional supplements combined with dietary counseling diminish whole body protein catabolism in HIV-infected patients. Eur J Clin Invest. 2000;30:87-94.

29. Koethe JR, Chi BH, Megazzini KM, Heimburger DC, Stringer JS. Macronutrient supplementation for malnourished HIV-infected adults: a review of the evidence in resource-adequate and resource-constrained settings. Clin Infect Dis. 2009;49:787-798.

30. Keating J, Bjarnarson I, Somasundaram S, et al. Intestinal absorptive capacity, intestinal permeability and jejunal histology in HIV and their relation to diarrhoea. Gut. 1995;37:623-629.

31. Pakkanen R, Aalto J. Growth factors and antimicrobial factors of bovine colostrum. Int Dairy J. 1997;7:285-297.

32. Rump JA, Arndt R, Arnold A, et al. Treatment of diarrhoea in human immunodeficiency virus-infected patients with immunoglobulins from bovine colostrum. Clin Invest. 1992;70:588-594.

33. Plettenberg A, Stoehr A, Stellbrink HJ, Albrecht H, Meigel W. A preparation from bovine colostrum in the treatment of HIV-positive patients with chronic diarrhea. Clin Invest. 1993;71:42-45.

34. Greenberg PD, Cello JP. Treatment of severe diarrhea caused by Cryptosporidium parvum with oral bovine immunoglobulin concentrate in patients with AIDS. J Acquir Immune Defic Syndr Hum Retrovirol. 1996;13:348-354.

35. Nord J, Ma P, DiJohn D, Tzipori S, Tacket CO. Treatment with bovine hyperimmune colostrum of cryptosporidial diarrhea in AIDS patients. AIDS. 1990;4:581-584.

36. Ungar BL, Ward DJ, Fayer R, Quinn CA. Cessation of Cryptosporidiumassociated diarrhea in an acquired immunodeficiency syndrome patient after treatment with hyperimmune bovine colostrum. Gastroenterology. 1990;98:486-489.

37. Larson BL. Immunoglobulins of the mammary secretions. In: Fox PF, editor. Advanced Dairy Chemistry-1: Proteins. New York, NY: Elsevier; 1992:231-254.

38. Playford R, Floyd D, Macdonald C, et al. Bovine colostrums is a health food supplementation which prevents NSAID induced gut damage. Gut. 1999;44:653-658.

39. Benheng $\mathrm{G}$, Chengxiang $\mathrm{L}$. Chemical composition of bovine colostrum. J Northeast Agr Univ. 1996;3:72-77.

40. Lai H, Lai S, Shor-Posner G, Ma F, Trapido E, Baum MK. Plasma zinc, copper, copper:zinc ratio and survival in a cohort of HIV-1 infected homosexual men. J Acquir Immune Defic Syndr. 2001;27:56-62. 
41. Baum MK, Shor-Posner G, Lai S, et al. High risk of HIV-related mortality is associated with selenium deficiency. J Acquir Immune Defic Syndr Hum Retrovirol. 1997;15:370-374.

42. Florén C-H, Chinenye S, Elfstrand L, Hagman C, Ihse I. ColoPlus, a new product based on bovine colostrum, alleviates HIV-associated diarrhoea. Scand J Gastroenterol. 2006;41:682-686.

43. Kaducu FO, Okia SA Upenytho G, Elfstrand L, Florén C-H. Effects of ColoPlus, a food product based on bovine colostrums, in the treatment of patients with HIV-associated diarrhea in Northern Uganda: A randomized controlled trial. Personal communication.
44. Elfstrand L, Lindmark-Månsson H, Paulsson M, Nyberg L, Åkesson B. Immunoglobulins, growth factors and growth hormone in bovine colostrum and the effects of processing. Int Dairy J. 2002;12: 879-887.

45. Antiretroviral therapy intensification with raltegravir and/or hyperimmune bovine colostrum in HIV-1 infected patients with suboptimal CD4+ T cell response: The CORAL study. Information is provided by The National Centre in HIV Epidemiology and Clinical Research. ClinicalTrials.gov Identifier NCT00772590.

\section{Publish your work in this journal}

HIV/AIDS - Research and Palliative Care is an international, peerreviewed open-access journal focusing on advances in research in HIV, its clinical progression and management options including antiviral treatment, palliative care and public healthcare policies to control viral spread. The journal welcomes original research, basic science, clinical \& epidemiological studies, reviews \& evaluations, expert opinion \& commentary, case reports \& extended reports. The manuscript management system is completely online and includes a very quick and fair peer-review system. Visit http://www.dovepress.com/ testimonials.php to read real quotes from published authors. 